\title{
INFLUENTIAL FACTORS OF EXISTING PHYSICAL EDUCATION CURRICULUM AT DEGREE LEVEL: A CASE STUDY OF KHYBER PAKHTUNKHWA
}

\author{
Sohail Roman ${ }^{1}$ and Mehreen Saba ${ }^{2}$
}

\begin{abstract}
The main purpose of the study was to assess the influential factors of existing physical education curriculum at degree level in Khyber Pakhtunkhwa. The study consisted of the population, twenty-seven (27) physical education teachers and Five Hundred \& Thirteen (513) physical education students, which were selected from Nine (09) randomly selected districts of Khyber Pakhtunkhwa. Survey technique was followed for the collection of required information. Appropriate questionnaire on Likert scale ranging from very much (VM) to Not at all (NAA) was developed and used after pilot testing checked through respondents of sampled colleges adopting a Cronbach's Alpha method of reliability. The responses of the respondents were supported by (SPSS), version 24.0. Statistical techniques like, Independent sample t-test, regression and ANOVA were applied for analyses of collected data. It has also been found that factors like class size, daily schedule/time table, available infrastructure and teachers' competency have significant influence upon teaching health and physical education. Based upon the findings, the researcher recommended that college administrator in collaboration with director colleges may bring manageable class size, allot adequate time for health and physical education classes, and provide required infrastructural facilities to impart the teaching experiences, observation and skills in a satisfying manner.
\end{abstract}

Keywords: Influential Factors, Affecting, Existing Physical Education Curriculum, and Case Study.

\section{INTRODUCTION}

\footnotetext{
${ }^{1}$ Lecturer DSSPE Sarhad University of Science and Information Technology, Peshawar; Email Address: sohail.ss@suit.edu.pk

${ }^{2}$ Lecturer DSSPE BZU, Multan: Email Address: 11.m.phill.2015@gmail.com
} 
Quality Physical Education (PE) depends on many influential factors, large class size, allocated time, available facilities and equipment, the contents of the PE curriculum, the number of students per teacher, and teacher competencies. Among these factors, we see that PE curriculum and its quality implementation are the determining factors of the PE outcomes. The official PE curriculums form the framework of possible interventions and in some cases can limit the effect of the subject. The PE curriculum under emphasizes health-related contents or considers them unintended collateral effects of the development of motor skills and the acquirement of sporting skills. The implementation of the curriculum, in contrast, depends on teachers' teaching competencies; our goal was to see whether specialist PE teachers' competencies have an effect on student's physical fitness and physical development by excluding the other four factors

\section{Historical Perceptive}

The size of the larger classes is a big factor that influences on the PE program. Instructors have tried to explain the number of students that should be found in a classroom for an effective learning experience, and to create a supportive relationship between teachers and students. According to Allington \& Johnston, (2002), class size is determined by various factors, such as the purpose of the lesson, the type of subject, the ability of the student, the physical possibilities, and the teaching method in a particular situation. The researcher further resume that teaching in a specific situation and teaching should be organized according to the nature of the topic and the goal should be achieved. When the number of students in a class exceeds the normal number, all the conditions of the teaching and learning process exceed the management capacity of the teacher and the head teacher. It is also difficult to create an environment conducive to learning inside and outside the classroom. For this reason, teachers are required to rely on a teaching methodology that is a reading method that is likely to prevent students from participating in the teaching process. 
Physical education is often faced with the challenge of inadequate facilities and poor education (Zusman, 2005). Most of countries are less well equipped and show signs of deterioration in supply. According to Hardman \& Marshall, (2005) the problem seems to go beyond geographical and economic limits: while the levels and standards of equipment and facilities are higher in economically developed countries, there are indicators of shortages and lack of equipment and maintenance in the college. College PE facilities are most be in available because widely used for recreational and / or community use after college hours.

The development of a rationale for the curriculum or a statement of educational philosophy is essentially a process of making the value orientation explicit. In this regard curriculum theorists (Lund \& Tannehill, 2010; Smart et al., 2001) urge that responsible for designing curricula to clarify programmed philosophy in order that those involved in implementing curricula can intentionally support and achieve the desired goals.

It is evident from the history of physical education and sport pedagogy that generally two curriculum goals have predominated: health-related fitness and skillful movement (Lund \& Tannehill, 2010). The author further states that these goals reflect primarily disciplinary mastery, and secondarily self-actualization. The task of the individual curriculum planner is to define fitness as a programmed objective, identify the fitness components of interest, set standards for educational achievement, and select appropriate assessment instruments (FraserThomas et al., 2005 \& Gould et al., 2002). Movement goals usually include mastery of basic or fundamental motor skills and skillful performance of selected sport, dance, gymnastic or physical recreation activities. The particular activities elected vary in accordance with interests and resources in different communities, geographic regions, and ethnic cultures (Pill et al., 2012). 
This is the scientific age and research-based knowledge is added to each and every discipline.

The discipline of health and physical education too needs new and research-based knowledge. In this regard, it is very much important to analyze the existing curriculum of health and physical education. This study is primarily aimed to evaluate the effectiveness of health and physical education curriculum at college level. Similarly, the researcher would analyze the influential factors with reference to the affective teaching of physical education in light of the views of concerned teachers and students in Government Degree Colleges of KP.

\section{STATEMENT OF THE PROBLEM}

It has been a matter of common observation that all aspects of life have been subject to modification and change. The field of physical education and sports sciences is not immune to these global changes that are posing new challenges. Hence, it is very much important to analyze the effectiveness of physical education curriculum with special reference to the growing demands. In this context, the researcher decided to work upon a study to assess the effectiveness and influential factors regarding existing physical education curriculum at government Degree College's level. This study was conducted at Government Degree College's in Khyber Pakhtunkhwa (KP), Pakistan. The researcher will address the situation with the help of appropriate questionnaire and the findings will provide base for providing recommendations in the betterment of health and physical education.

\section{OBJECTIVES OF THE STUDY}

1. To find out the effect of different factors i.e., class size, daily schedule, facilities and equipment and teacher's competency on existing physical education curriculum at college level in KP. 
2. To determine the effect of different factors i.e, class size, daily schedule, facilities and equipment and teacher's competency on existing physical education curriculum at college level in KP.

3. To compare the responses of teachers and students regarding the effect of different factors i.e, class size, daily schedule, facilities and equipment and teacher's competency on existing physical education curriculum at college level in KP.

\section{RESEARCH HYPOTHESES}

H 1 Class size has significant impact on teaching existing physical education curriculum at degree level as perceived by the respondents.

H 2 Daily schedule has significant impact on teaching existing physical education curriculum at degree level as perceived by the respondents.

H 3 Existing equipment and facilities significant impact on teaching existing physical education curriculum at degree level as perceived by the respondents.

H4 Teacher's competency has significant impact on teaching existing physical education curriculum at degree level as perceived by the respondents.

H 5 There is significant mean difference between the responses of teachers and students regarding the influential factors of existing physical education curriculum on various dimensions i.e., class size, daily schedule, equipment and facilities and teacher's competency.

\section{SIGNIFICANCE OF THE STUDY}

The influential factors of any educational program depends on a thorough understanding of the problems that inhibit its successful accomplishment. Therefore, the problems that were discussed in this study have the following importance. The study has significant contribution in the identification of the factors that affects quality of teaching physical education in 
Government Degree College's level in Khyber Pakhtunkhwa (KP), Pakistan. The findings of the study are expected to create awareness to the problem in perspective of teaching health and physical education among physical educators in particular and the public at large. Moreover, the findings of the research study has significant role in providing pathways to the concerned bodies in order to find out the solution for the problems that delay quality of teaching physical education at degree level in the concerned areas. This research has significance on the ground to stimulate the interest of individuals to conduct research on the factors that affect the quality of teaching physical education for further investigation.

\section{LIMITATIONS}

1. Different factors involved in the research process such as stipulated time, expenditure and academic pressure; it became limitation to contact all the degree colleges in the Khyber Pakhtunkhwa.

2. As the study was conducted in the province of KP, therefore; the generalizability of the findings in other provinces became limitation of the study.

3. The study at hand was focused on the curriculum of health and physical education at degree level. Therefore, the findings may not be generalized upon other levels i.e, school and university.

4. The collection of $100 \%$ responses from the sampled respondents was another limitation of the study.

\section{DELIMITATIONS}

1. The study at hand was primarily delimited to (09) randomly selected district of Khyber Pakhtunkhwa.

2. The study was confined to a sample of $n=540$ (teachers $=27$ and students $=513$ ) which was conveniently selected and included in the study. 
3. Self-made questionnaire based on the researcher' personal observation, exiting literature and opinion of the physical education teachers was developed and used for the collection of needed information.

4. The study was facilitated by quantitative research method with cross-sectional survey.

\section{METHODS AND MATERIAL}

The researcher has adopted following procedures in order to assess the effectiveness of physical education curriculum and influential factors in teaching physical education a various college of Khyber Pakhtunkhwa (KP).

\section{Research Method and Data Collection Technique}

Keeping into consideration, the present study was supported by quantitative research method with cross-sectional survey. Therefore, the researcher followed survey technique for collecting needed information.

\section{Population of the Study}

The population for this study comprised of teachers and students in degree colleges of Khyber Pakhtunkhwa. The researcher has confined his study only to boy's government degree colleges through the process of delimitation.

\section{Sample and Sampling}

Therefore, the researcher selected a representative sample from the whole population to collect more authentic and reliable information.

The population of this research study comprised on teachers and students of government degree colleges in the province of Khyber Pakhtunkhwa (KP). There are 26 districts in the province of $\mathrm{KP}$ in which the total number of male colleges is 97 . As the study was concerned with vast 
number of population and it was unmanageable to contact all of them. Hence, the researcher has confined his study to a stipulated number of respondents through the process of sampling. The researcher divided the province into three regions i.e., southern region, central region and northern region. A representative sample size was selected from each of the region. For this purpose, the researcher selected three (03) districts from each region and similarly, three (03) colleges from each district randomly for equal representation. Finally, twenty respondents (1 physical education teacher and 19 students) from each college were conveniently selected and participated in the study. Thus, a sample of 540 (physical education teachers $=27$ and students $=$ 513) was selected from government boy's degree colleges, Khyber Pakhtunkhwa, Pakistan.

\section{Instrument and Instrumentation}

The term instrument is used for assessing device whereas, instrumentation is the whole process of preparing device for the purpose of data collection (Wilkinson \& Birmingham, 2003). The quality of instrument has significant role in collecting reliable information and the obtained conclusion are based on the information collected through instrument.

\section{Data Collection Instrument}

Based on the researcher's personal observation, related research articles, supervisor's suggestions and the opinion of the physical educationists as well as students, the researcher developed a questionnaire for the collection of required information. The detailed is given below.

\section{Factors Affecting Health and Physical Education Curriculum Questionnaire (FAHPECQ)}

Similarly, the second questionnaire was developed and used with the intention to assess the effects of different factors i.e., class size, daily schedule, equipment and facilities and teacher's competency with reference to the teaching existing health and physical education curriculum at college level in KP. 


\section{Validity and Reliability}

Supervisor suggestions and expert's opinion of sports sciences and physical education and other disciplines were obtained to determine the Content Validity of the instrument. The reliability measures were assessed through Cronbach's Alpha and found .845 respectively.

\section{Procedure of Data Collection}

Prior to data collection, the researcher had obtained authority letter of the Head of the Department (HOD) to collect the data from the sampled college. The authority letter was then sent to all the principals of selected colleges in order to get permission as well as cooperation was sought in connection with the collection of data. Before distribution of the scale, the researcher verbally explained the purpose of his visit. Respondents were asked to carefully read the questionnaires, respond to all the statements included in the questionnaires and return the same within a week time. In this way, they were assured that the gathered information would be used for research purpose only.

\section{DATA ANALYSES}

With the intention of testing hypotheses, data collected were analyzed by using descriptive and inferential statistical methods using the Statistical Packages for Social Sciences (SPSS) version 24.0.

H1 Class size has significant impact on teaching existing physical education curriculum at degree level as perceived by the respondents.

Table 1: Regression showing the impact of class size on existing physical education curriculum.

\begin{tabular}{lccccc}
\hline Model & R & R Square & Adjusted R Square & F & Sig. \\
\hline 1 & .321 & .103 & .101 & 61.798 & $.000^{\mathrm{b}}$ \\
\hline
\end{tabular}

Predictor: Class Size 
Criterion: Existing Physical Education Curriculum

Coefficients

\begin{tabular}{|c|c|c|c|c|c|}
\hline \multirow{2}{*}{$\begin{array}{c}\text { Model } \\
1\end{array}$} & \multicolumn{2}{|c|}{ Unstandardized Coefficients } & \multirow{2}{*}{$\frac{\text { Standardized Coefficients }}{\text { Beta }}$} & \multirow[t]{2}{*}{$\mathbf{t}$} & \multirow[t]{2}{*}{ Sig. } \\
\hline & B & Std. Error & & & \\
\hline (Constant) & 1.978 & .105 & & 18.915 & .000 \\
\hline Class Size & 0.294 & .037 & .321 & 7.861 & .000 \\
\hline
\end{tabular}

$\alpha=0.05$

According to table no, 1 the class size has significantly impact upon the existing PE curriculum. $\mathrm{R}^{2}$ in the above table shows that there is $10 \%$ impact on existing PE curriculum is due to class size. In $1^{\text {st }}$ column in the coefficients table depict that, if one unit increase in class size then it will cause 0.294 units' variation in existing PE curriculum. Statistically, class size significantly predicted on existing PE curriculum, $\mathrm{B}=0.294, \mathrm{t}(538)=\mathrm{p}<0.01$. Class size also explained the significant proportion of variance in existing PE curriculum: $\mathrm{R}^{2}=.103, \mathrm{~F}(2,538)=61.798$, $\mathrm{p}<0.01$. The above table indicated that the alternate hypothesis is here by accepted.

H2 Daily schedule has significant impact on teaching existing physical education curriculum at degree level as perceived by the respondents.

Table 2: Regression showing the impact of daily schedule on existing physical education curriculum.

\begin{tabular}{llcccc}
\hline Model & R & R Square & Adjusted R Square & F & Sig. \\
\hline 1 & .261 & .068 & .067 & 39.4614 & $.000^{\mathrm{b}}$ \\
\hline
\end{tabular}

Predictor: Daily Schedule

Criterion: Existing Physical Education Curriculum

Coefficients

Model Unstandardized Coefficients $\underline{\text { Standardized Coefficients }}$ t Sig.

1 B $\quad$ Std. Error Beta




\begin{tabular}{llllll}
$($ Constant $)$ & 2.58 & .101 & & 21.277 & .000 \\
Daily schedule & .227 & .036 & .261 & 6.282 & .000 \\
\hline
\end{tabular}
$\alpha=0.05$

Table 2 shows that daily schedule has significantly impact upon the existing physical education curriculum. $\mathrm{R}^{2}$ in the above table shows that there is $6 \%$ impact on existing PE curriculum is due to daily schedule. According to the coefficient table, if one unit increases in the daily schedule then it will cause 0.227 units variation in existing PE curriculum. Statistically, daily schedule significantly expected on existing PE curriculum, $B=0.227, t(538)=p<0.01$. Daily schedule also explained the significant proportion of variance in existing PE curriculum: $\mathrm{R}^{2}=$ $.068, \mathrm{~F}(2,538)=39.461, \mathrm{p}<0.01$. The above table signposts that the alternate hypotheses is at this point accepted.

H 3 Existing equipment and facilities significant impact on teaching existing physical education curriculum at degree level as perceived by the respondents.

Table 3: Regression showing the impact of equipment and facilities on existing physical education curriculum.

\begin{tabular}{llcccc}
\hline Model & R & R Square & Adjusted R Square & F & Sig. \\
\hline 1 & .346 & .120 & .118 & 73.049 & $.000^{\mathrm{b}}$ \\
\hline
\end{tabular}

Predictor: Equipment and Facilities

Criterion: Existing Physical Education Curriculum

\section{Coefficients}

\begin{tabular}{|c|c|c|c|c|}
\hline Model & dardize & fficients & Standardized Coefficients & Sig. \\
\hline 1 & B & Std. Error & Beta & \\
\hline (Constant) & 1.963 & .098 & & 19.967 .000 \\
\hline Daily schedule & .286 & .033 & .346 & 8.547 .000 \\
\hline
\end{tabular}
$\alpha=0.05$ 
Table 3 shows that, equipment and facilities has significantly impact upon the existing PE curriculum. $\mathrm{R}^{2}$ in the above table shows that, there is $12 \%$ impact on existing PE curriculum is due to equipment and facilities. According to the coefficients table signify that, if one unit increase in equipment and facilities then it will cause 0.286 units variation in existing PE curriculum. Statistically, equipment and facilities significantly estimated on existing PE curriculum, $\mathrm{B}=0.286, \mathrm{t}(538)=\mathrm{p}<0.01$. Equipment and facilities correspondingly explained the significant fraction of variance in existing PE curriculum: $\mathrm{R}^{2}=.120, \mathrm{~F}(2,538)=73.049$, $\mathrm{p}<0.01$. Henceforth, the alternate hypotheses is here by accepted.

\section{H4 Teacher's competency has significant impact on teaching existing physical education} curriculum at degree level as perceived by the respondents.

Table 4: Regression showing the impact of teacher's competency on existing physical education curriculum

\begin{tabular}{lccccc}
\hline Model & R & R Square & Adjusted R Square & F & Sig. \\
\hline 1 & .266 & .071 & .69 & 41.011 & $.000^{\mathrm{b}}$ \\
\hline
\end{tabular}

Predictor: Teachers Competency

Criterion: Existing Physical Education Curriculum

\section{Coefficients}

\begin{tabular}{lcccccc} 
Model & \multicolumn{2}{l}{ Unstandardized Coefficients } & & Standardized Coefficients & t & Sig. \\
\cline { 2 - 3 } $\mathbf{1}$ & $\mathbf{B}$ & Std. Error & \multicolumn{1}{c}{ Beta } & & & \\
\hline (Constant) & 2.055 & .115 & & 17.832 & .000 \\
Daily schedule & 0.256 & .040 & .266 & 6.404 & .000 \\
\hline
\end{tabular}
$\alpha=0.05$ 
Table 4 shows that, teachers' competency has significantly impact upon the existing PE curriculum. $\mathrm{R}^{2}$ in the above table shows that, there is $7 \%$ impact on existing PE curriculum is due to teacher's competency. According to the coefficients table signify that, if one unit increase in teacher's competency then it will cause 0.256 units variation in existing PE curriculum. Statistically, equipment and facilities significantly estimated on existing PE curriculum, $\mathrm{B}=0.256, \mathrm{t}(538)=\mathrm{p}<0.01$. Teacher's competency consistently explained the significant portion of variance in existing PE curriculum: $\mathrm{R}^{2}=.71, \mathrm{~F}(2,538)=41.011, \mathrm{p}<$ 0.01. The above table identified that the alternate hypotheses is hereby accepted.

H5 There is significant mean difference between the responses of teachers and students regarding the influential factors of existing physical education curriculum on various dimensions i.e., class size, daily schedule, equipment and facilities and teacher's competency.

Table 5: ANOVA showing the most dominant factor which effect existing physical education curriculum at degree level

\begin{tabular}{lccccc}
\hline Influential factors & N & Mean & Std. D & F & Sig. \\
\hline Class Size & 540 & 2.70 & .76 & & \\
Daily Schedule & 540 & 2.68 & .80 & & \\
Equipment and Facilities & 540 & 2.81 & .84 & 3.814 & .010 \\
Teacher Competency & 540 & 2.79 & .72 & & \\
\hline
\end{tabular}
$\alpha=0.05$

The effect of different factors on existing physical education curriculum was not same because the $\mathrm{F}(3,537)=3.814, \mathrm{P}<0.05$. The above table also indicated that descriptively the influence of Equipment and facilities is greater than the influence of class size, daily schedule, and equipment and facilities $(2.81>2.70,2.68 \& 2.79)$. Accordingly, the most dominant factor 
which influenced teaching existing physical education curriculum at college was equipment and facilities. Hence the alternate hypothesis is hereby rejected.

\section{DISCUSSION}

The study has proved that both the teachers and students did not perceive a very positive impact on the existing physical education curriculum in the development and improvement of physical fitness. The researcher observed very little attention on practical of health and physical education. During contact with students, most of them replied that practical classes do not conduct on a regular basis. Physical education is practically oriented discipline in which proper emphasis may be given to both theory and practical classes (Kyriacou, 1997).

The researcher analyzed the responses of the population regarding the influence of class size upon seeking physical education and most of the teachers and students agreed that large student's size impede in achieving objectives of the course. It is evident from Gross (2009) that the size of the class can influence or create hindrance in imparting the activities of physical education. Various researches have suggested that effective teaching and learning can take place under feasible and appropriate condition where both teacher and students feel comfortable (Gibbs \& Simpson, 2005; Biggs, 2011). It is also concluded that the majority respondents perceived that large size of the class make difficulty for teacher in their communication process. The findings associate with the findings of Morgan and Hansen (2008) who have demonstrated that learning is a two way process and depends upon communication between teachers and taught. The author has further substantiated that the large size of the class create difficulties in the mutual communication between teachers and students, which ultimately hinders the effectiveness of teaching the quality physical education.

The allotment of sufficient periods for health and physical education is an intense problem at degree college level. The majority respondents perceived that improper time allocation for 
physical education classes create disinterest among the students as well as teacher which may lead ineffectiveness of the program. Research has proposed that the academic learning is mainly dependent on the effective time management (Alavi, \& Leidner, 2001). Regarding allocation of instructional time for teaching health and physical education, Kennedy (2010) has proposed that the head of institution should have allotted necessary time to be spent in relation to the course content to be taught by the physical education teacher. Similarly, Reston (2004) has proposed that adequate time might be allotted to impart the course contents of physical education satisfactorily. The author has further suggested that adequate time per week may be allotted to the subject of physical education at various level of education.

The impact of existing facilities upon teaching health and physical education curriculum was analyzed through different questions and the data revealed that the existing facilities like playing facilities, financial facilities and existing infrastructure have significant influences upon teaching the existing health and physical education curriculum at college level in the sampled colleges of Khyber Pakhtunkhwa. In response to the above findings, Jamieson (2003) has suggested that required facilities might be provided to take the teaching and learning process effectively. Likewise, Pate et al. (2006) have recommended that availability of required facilities may be ensured to get maximum benefits of teaching health and physical education curriculum, whereas Balyi, Way and Higgs (2013) have found that improper and insufficient facilities can have negative impact upon teaching and learning physical education, sports, athletic and recreation.

Teacher is responsible for the effectiveness of learning program. Therefore, the teachers should have communication skills in order to deliver his knowledge, observation and experiences in a satisfactory way. Most of respondents replied that factors like teachers convincing power, qualifications and communication skills have an impact upon teaching the existing curriculum of health and physical education at college level. Same findings have been found by Avalos 
(2011) who stated that physical education teacher's knowledge, observation and experiences affects the quality of teaching health and physical education curriculum. In light of the above, Pianta et al (2005) has substantiated that teacher's knowledge, qualification, subject command and way of teaching are the determinants of effective teaching. Similarly, Cushion, Armour and Jones (2003) have stated that the better educated the teaching staff the better they able to impart their experiences with students.

\section{CONCLUSION}

The study was conducted to assess the influential factors of existing physical education curriculum and researcher also investigate the factors that affect teaching health and physical education at degree college level in Khyber Pakhtunkhwa. The data shows that both the categories of respondents i.e., teachers and students considered health and physical education as an important subject for the overall development of students. It has been concluded that respondents (teachers and students) perceived that factors like class size, daily schedule/time table, available infrastructure and teachers' competency have significant influence upon teaching health and physical education. Uniformity in the perception was found with reference to the dominant effect of existing infrastructure in the shape of equipment upon teaching health and physical education curriculum at degree level in Khyber Pakhtunkhwa.

\section{RECOMMENDATIONS}

1. The study has revealed that the large class size has a significant influence upon teaching health and physical education, therefore the researcher recommended that the college administrator in collaboration with director colleges may bring manageable class size to impart the teaching experiences, observation and skills in a satisfying manner. 
2. The study has found that the required facilities for teaching health and physical education did not provide the vast majority of the colleges. Therefore, provision of required facilities in and outside the classrooms is frequently recommended.

3. The study has shown that the allotment of periods for health and physical education subject has serious issue. Therefore, the researcher recommended that the concerned officials may arrange sufficient periods in a week; so that the full outcomes can be passed on to the students.

4. The most important factor in an effective teaching is the teacher's competency. For this purpose, arrangement of workshops and seminars may be arranged by the school administration in collaboration with director colleges in order to equip the physical education teachers with innovative teaching strategies. 


\section{REFERENCES}

Achinstein, B., \& Aguirre, J. (2008). Cultural match or culturally suspect: How new teachers of color negotiate sociocultural challenges in the classroom. Teachers College Record, 110(8), 1505-1540.

Eccles, J. S. (2004). Schools, academic motivation, and stage-environment fit. Handbook of adolescent psychology, 2, 125-153.

Fraser-Thomas, J. L., Côté, J., \& Deakin, J. (2005). Youth sport programs: An avenue to foster positive youth development. Physical Education \& Sport Pedagogy, 10(1), 19-40.

Galassi, J. (2017). Strengths-based school counseling: Promoting student development and achievement. Routledge

Gould, D., Dieffenbach, K., \& Moffett, A. (2002). Psychological characteristics and their development in Olympic champions. Journal of applied sport psychology, 14(3), 172204. Grade classrooms. Guilford Press.

gaming during physical education classes.

Hardman, K. (2011). Global issues in the situation of physical education schools. Contemporary issues in physical education, 11-29.

Johnson, C., Baird, R., Dougherty, P. E., Globe, G., Green, B. N., Haneline, M., \& Lisi, A. J. (2008). Chiropractic and public health: current state and future vision.

Kelly, L., \& Melograno, V. (2004). Developing the physical education curriculum: An achievement-based approach. Human kinetics.

Komives, S. R., Lucas, N., \& McMahon, T. R. (2009). Exploring leadership: For college students who want to make a difference. John Wiley \& Sons.

Lund, J., \& Tannehill, D. (2010). Standards-based physical education curriculum development. Jones \& Bartlett Learning. 
Lund, J., \& Tannehill, D. (Eds.). (2010). Standards-based physical education curriculum development. Jones \& Bartlett Learning.

Pill, S., Penney, D., \& Swabey, K. (2012). Rethinking sport teaching in physical education: A case study of research based innovation in teacher education.

Sallee, M. W., \& Tierney, W. G. (2007). The influence of peer groups on academic success. College and University, 82(2),

Schempp, P. G. (2003). Teaching sport and physical activity: Insights on the road to excellence. Human Kinetics.

Schneider, T. W., \& Klotz, J. (2000). The Impact of Music Education and Athletic Participation on Academic Achievement.

Smart, J. C., Feldman, K. A., \& Ethington, C. A. (2000). Academic disciplines: Holland's theory and the study of college students and faculty. Vanderbilt University Press.

Wallhead, T. y O'Sullivan, M. "Sport Education: Physical Education for the new millennium?” Physical Education \& Sport Pedagogy, vol.10 (2), 181-210. 2005. 